\title{
PERBEDAAN PENGARUH HIDROGEN PEROKSIDA 35\% DAN KARBAMID PEROKSIDA 35\% TERHADAP MICROLEAKAGE PADA RESIN KOMPOSIT NANOHYBRID
}

Istianah $^{\star}$, Endah Aryati Ekoningtyas ${ }^{* *}$, Benni Benyamin ${ }^{* *}$

\begin{tabular}{c}
\hline Keywords: \\
intracoronal bleaching, \\
hydrogen peroxide $35 \%$, \\
carbamide peroxide \\
$35 \%$, microleakage, \\
nanohybrid composite \\
resin
\end{tabular}

\section{ABSTRACT}

Background: Intrinsic tooth discoloration is an aesthetic problem for most people. One of the Intracoronal bleaching treatment used hydrogen peroxide $35 \%$ and carbamide peroxide $35 \%$. Tooth whitening material reported increase microleakage in composite resin. Purpose: This research aims to determine the differences effect of hydrogen peroxide $35 \%$ and carbamide peroxide 35 $\%$ toward microleakage in the nanohybrid composite resin. Method: This research was an experimental laboratory method with post test only control group design. The research was conducted by doing the root canal treatment on 27 samples of maxillary central incisor with the base, then the procedure of intracoronal bleaching was done using hydrogen peroxide $35 \%$ as group 1 , carbamide peroxide $35 \%$ as group 2 and distilled water as control group. After nanohybrid composite resin restorative procedure, coated with nail varnish then immersion in methylene blue $5 \%$. Furthermore, slit the teeth and methylene blue penetration depth measured using metalography microscope. Result: Based on one way ANOVA test found that there was a difference in each group with a significance of $0,000(p<0,05)$ it can be interpreted that there are differences between groups. Based on LSD Post Hoc test, found that there was a difference in the effect on the group of hydrogen peroxide $35 \%$ and carbamide peroxide $35 \%$ with a significance of $0,004 \quad(p<0,05)$. Conclusion: The results of this research can be concluded that there was differences in the effect of hydrogen peroxide $35 \%$ and carbamide peroxide $35 \%$ toward microleakage in the nanohybrid composite resin.

\section{PENDAHULUAN}

Perubahan warna gigi merupakan masalah estetik pertama bagi sebagian besar masyarakat. Perubahan warna gigi bisa secara intrinsik dan ekstrinsik. Perubahan intrinsik merupakan perubahan warna pada bagian dalam struktur gigi misalnya pada gigi non vital. Sedangkan perubahan ekstrinsik merupakan perubahan warna pada permukaan luar gigi 1. Salah satu bentuk perawatan pada gigi yang mengalami perubahan warna yang sering dilakukan adalah pemutihan gigi (dental bleaching). Pemutihan gigi merupakan alternatif konservatif untuk mengembalikan fungsi estetik dari gigi yang mengalami perubahan warna sehingga dapat dicapai warna gigi yang lebih terang ${ }^{2}$.
Perawatan yang dilakukan pada perubahan warna pada gigi non vital adalah Intracoronal bleaching. Intracoronal bleaching dilakukan pada gigi yang telah dirawat endodontik dengan meletakkan bahan bleaching dalam kamar pulpa. Intracoronal bleaching dapat dilakukan dengan walking bleach dan termokatalitik atau kombinasi kedua teknik tersebut. Teknik walking bleach memakai hidrogen peroksida $30-35 \%$ atau campuran hidrogen peroksida $30-35 \%$ dan natrium perborat yang dimasukkan dalam kamar pulpa.3 Bahan in-office bleaching yang biasa dipakai yaitu hidrogen peroksida $35 \%$ dan karbamid peroksida 35\% dilaporkan dapat dijadikan bahan intracoronal bleaching ${ }^{4}$.

Perawatan bleaching pada gigi non vital membutuhkan pembuangan jaringan pulpa,

*Program Pendidikan Dokter Gigi Fakultas Kedokteran Gigi Unissula Semarang, ** Staff Pengajar Fakultas

Kedokteran Gigi Universitas Islam Sultan Agung Semarang

Korepondensi: istianah.202@std.unissula.ac.id 
dentin nekrotik, dan jaringan keras gigi dalam jumlah besar, sehingga dapat menurunkan retensi (kemampuan restorasi tidak lepas) dan resistensi (kemampuan restorasi menahan beban kunyah). Hal ini menyebabkan sering terjadinya kegagalan dari restorasi setelah perawatan endodontik. Kegagalan restorasi yang sering terjadi diantaranya kebocoran tepi, lepasnya restorasi, fraktur pada restorasi, dan fraktur gigi 5 .

Restorasi resin komposit adalah bahan restorasi estetis yang digunakan untuk restorasi one visit terutama di anterior. Kandungan utama resin komposit yaitu matriks resin, partikel pengisi (filler) dan bahan coupling silane. Klasifikasi resin komposit berdasarkan ukuran partikel filler ada 4 yaitu resin komposit Makrofill, Mikrofill, Hibrid dan Hibrid partikel kecil (Smallparticle hybrid). Jenis resin komposit terbaru yang sedang dikembangkan saat ini adalah resin komposit nanohybrid. Resin komposit Nanohybrid merupakan salah satu jenis resin komposit hybrid yang mengandung partikel filler yang berukuran nano (0.005-0.01 mikron) pada matriks resinnya. Dengan ukuran partikel yang lebih kecil, nano hibrid resin komposit mempunyai hasil akhir yang lebih baik bila dinilai dari tekstur permukaan komposit, shrinkage lebih sedikit, dan perubahan warna lebih sedikit ${ }^{6}$. Akan tetapi resin komposit memiliki kekurangan yaitu sifat pengerutan saat polimerisasi dan koefisien termal ekspansinya yang tinggi ${ }^{\text {. }}$.

Bahan aktif bleaching yaitu hidrogen peroksida bersifat sangat reaktif yang menimbulkan pengaruh terhadap bahan restorasi seperti amalgam, porcelain, glass ionomer cement, compomer dan resin komposit ${ }^{8}$. Ellias dan Sajjan (2002) menyatakan bahwa bleaching dapat menyebabkan microleakage dari restorasi resin komposit. Microleakage terjadi karena sisa $\mathrm{H}_{2} \mathrm{O}_{2}$ (residual peroksida) menghambat polimerisasi bahan bonding resin sehingga terbentuk celah antara gigi dengan resin komposit dan akan menurunkan kekuatan adhesi resin komposit pada gigi ${ }^{9}$.

Dari uraian tersebut diatas maka penulis tertarik untuk meneliti tentang perbedaan pengaruh hidrogen peroksida 35\% dan karbamid peroksida $35 \%$ terhadap microleakage pada resin komposit nanohybrid.

\section{METODE PENELITIAN}

Rancangan penelitian post test dengan kelompok kontrol (post test only control group design) di Laboratorium Skill Fakultas Kedokteran Gigi Universitas Islam Sultan Agung, Laboratorium Mikrobiologi Fakultas Kedokteran Universitas Islam Sultan Agung, dan Laboratorium Bahan Teknik Jurusan Teknik Mesin dan Industri Fakultas Teknik Universitas Gadjah Mada. Sampel yang digunakan adalah gigi insisivus sentral rahang atas pasca ekstraksi. Sampel gigi dilakukan prosedur PSA dan diberi basis. Selanjutnya, sampel dibagi menjadi 3 kelompok. Kelompok 1 diaplikasikan hidrogen peroksida 35\%, kelompok 2 diaplikasikan karbamid peroksida $35 \%$, dan kelompok 3 (kontrol) diaplikasikan aquadest. Aplikasi bahan pemutih dengan cara memasukkan dalam cotton pellet dan diletakkan dalam kamar pulpa. Kemudian sampel gigi tumpat sementara dan disimpan di inkubator selama 7 hari. Bahan pemutih diambil dan disimpan dalam inkubator selama 2 minggu. Selanjutnya, dilakukan prosedur penumpatan menggunakan resin komposit nanohybrid dan di simpan di inkubator selama 24 jam. Kemudian dilakukan perendaman dengan methylen blue 5\% selama 4 jam dan pembelahan gigi secara longitudinal. Selanjutnya, microleakage diukur dengan mengamati kedalaman penetrasi methylen blue pada sampel di bawah mikroskop metalography dengan perbesaran 50x.

Hasil data yang diperoleh, dianalisis menggunakan SPSS. Kemudian diuji normalitas data dengan uji Shapiro-Wilk dan diuji homogenitas data dengan uji Levene. Jika data homogen dan normal maka menggunakan uji One-Way ANOVA, kemudian untuk menguji perbedaan rerata antar kelompok uji digunakan uji Post Hoc LSD. 


\section{HASIL PENELITIAN}

Hasil penelitian menunjukkan bahwa hidrogen peroksida 35\%, karbamid peroksida $35 \%$ dan aquadest memiliki kemampuan microleakage yang ditunjukkan dengan adanya penetrasi zat pewarna seperti gambar berikut:

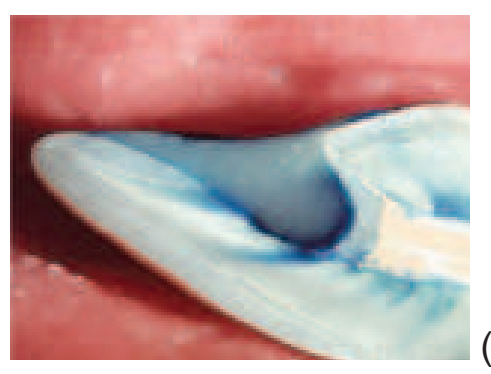

(a)

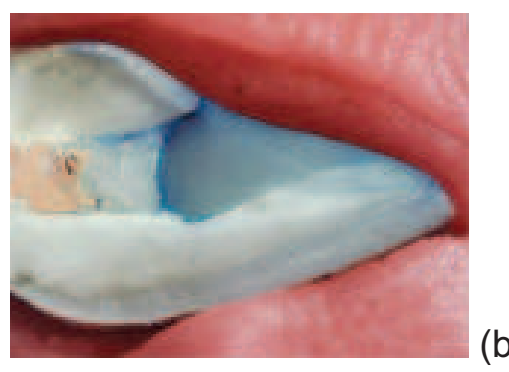

(b)

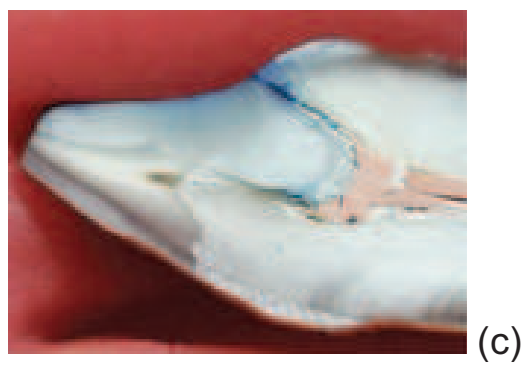

Gambar 1. Penetrasi zat pewarna pada sampel (a) Hidrogen Peroksida 35\%, (b) Karbamid Peroksida 35\%, (c) kontrol (aquadest)

Rata-rata nilai kedalaman microleakage pada kelompok hidrogen peroksida $35 \%$ yaitu $8,4878 \mathrm{~mm}$, pada kelompok karbamid peroksida $35 \%$ yaitu $7,1411 \mathrm{~mm}$ dan pada kelompok kontrol yaitu $5,7956 \mathrm{~mm}$ seperti yang terdapat pada tabel 1. Dari data hasil pengukuran nilai kedalaman microleakage kemudian dilakukan uji normalitas dengan uji Shapiro-Wilk dengan hasil pada tabel 2 .
Tabel 1. Pengukuran nilai kedalaman microleakage pada 3 kelompok perlakuan

\begin{tabular}{ccc}
\hline Kelompok & $\begin{array}{c}\text { Rata- } \\
\text { rata }\end{array}$ & $\begin{array}{c}\text { Standar } \\
\text { Deviasi }\end{array}$ \\
\hline Hidrogen Peroksida 35\% & 8,4878 & 0,73314 \\
Karbamid Peroksida 35\% & 7,1411 & 0,46194 \\
Kontrol & 5,7956 & 1,26902 \\
\hline
\end{tabular}

Tabel 2. Hasil Uji Shapiro Wilk

\begin{tabular}{cc}
\hline Kelompok & Sig \\
\hline Hidrogen Peroksida 35\% & 0,260 \\
Karbamid Peroksida 35\% & 0,195 \\
Kontrol & 0,086 \\
\hline
\end{tabular}

Hasil analisis dengan uji Shapiro Wilk menunjukkan bahwa semua kelompok memiliki nilai $p>0,05$ sehingga data terdistribusi normal. Selanjutnya, dilakukan uji homogenitas dengan hasil sebagai berikut.

Tabel 3. Hasil Uji Levene

\begin{tabular}{ll}
\hline & Sig \\
\hline Microleakage & 0,102 \\
\hline
\end{tabular}

Hasil uji homogenitas dengan uji Levene menunjukkan nilai $0,102(p<0,05)$ menunjukkan bahwa data homogen. Jadi, dari hasil uji normalitas dan homogenitas menunjukkan bahwa data terdistribusi normal dan homogen.

Berdasarkan uji one way ANOVA didapatkan ada perbedaan pada masing-masing kelompok dengan signifikansi $0,000 \quad(p<0,05)$ sehingga dapat diinterpretasikan bahwa terdapat perbedaan kedalaman microleakage antar kelompok hidrogen peroksida 35\%, karbamid peroksida 35\% dan aquadest.

Tabel 4. Hasil Uji One Way ANOVA

\begin{tabular}{cc}
\hline Microleakage & Sig \\
\hline Antar Kelompok & 0,000 \\
\hline
\end{tabular}


Berdasarkan uji Post Hoc LSD, didapatkan ada perbedaan pengaruh pada kelompok hidrogen peroksida $35 \%$ dan karbamid peroksida $35 \%$ dengan signifikansi $0,004(p<0,05)$.

Tabel 5. Hasil uji Post Hoc LSD

\begin{tabular}{ccc}
\hline Kelompok & Kelompok & Sig \\
\hline Hidrogen Peroksida 35\% & Karbamid Peroksida 35\% & 0,004 \\
Hidrogen Peroksida 35\% & Kontrol & 0,000 \\
Karbamid Peroksida 35\% & Kontrol & 0,004 \\
\hline
\end{tabular}

\section{DISKUSI}

Hasil analisa statistik didapatkan bahwa terdapat perbedaan signifikan antara kelompok hidrogen peroksida $35 \%$, karbamid peroksida $35 \%$ dan aquadest terhadap microleakage pada resin komposit nanohybrid. Hal ini sesuai dengan penelitian Ellias dan Sajjan (2002), bahwa prosedur intracoronal bleaching dapat meningkatkan microleakage pada restorasi resin komposit. Microleakage terjadi karena residual peroksida yang mengandung oksigen, terjebak di email dan dentin yang dilepaskan selama bleaching dapat menghambat polimerisasi resin komposit ${ }^{9}$. Polimerisasi terdiri dari tahap inisiasi, propagasi, terminasi. Tahap inisiasi adalah tahap dimana kompleks monomerradikal bebas untuk menciptakan rantai awal. Tahap propagasi adalah tahap dimana kompleks monomer-radikal bebas bertemu dengan monomer lain dan membentuk suatu rantai polimer. Tahap terminasi adalah tahap dimana 2 radikal bebas saling berinteraksi dan membentuk ikatan kovalen yang stabil. Oksigen yang terjebak di email dan dentin akibat residual peroksida menyebabkan terjadinya terminasi dini, sehingga proses polimerisasi tidak terjadi sempurna dan menimbulkan celah di interface resin-gigi. Terminasi dini adalah tertutupnya rantai yang terlalu cepat akibat terpaparnya oksigen sehingga tidak terbentuk ikatan yang stabil ${ }^{10}$.

Dari data hasil penelitian juga diketahui nilai microleakage restorasi resin komposit pada kelompok hidrogen peroksida $35 \%(8,4878)$ lebih tinggi dibandingkan kelompok karbamid peroksida $35 \%(7,1411 \mathrm{~mm})$ dan kelompok kontrol $(5,7956 \mathrm{~mm})$. Hal ini dikarenakan hidrogen peroksida memiliki agen oksidasi yang kuat sehingga memiliki kemampuan destruktif yang berlebih pada dentin ${ }^{11}$. Hidrogen peroksida $\left(\mathrm{H}_{2} \mathrm{O}_{2}\right)$ sebagai agen oksidator mempunyai radikal bebas yang tidak mempunyai pasangan elektron yang akan lepas dan kemudian diterima oleh email dan dentin sehingga terjadi reaksi oksidasi. Radikal bebas dari peroksida adalah perhidroksil $\left(\mathrm{HO}_{2}\right)$ dan oksigenase $(\mathrm{O})$. Reaksi penguraian hidrogen peroksida menjadi radikal bebas adalah sebagai berikut:

$$
\mathrm{H}_{2} \mathrm{O}_{2} \rightarrow \mathrm{HOO}^{+}+\mathrm{O}^{-}
$$

Sedangkan reaksi penguraian hidrogen peroksida terhadap molekul gigi adalah sebagai berikut:

$\mathrm{H}_{2} \mathrm{O}_{2}+\mathrm{Ca}_{10}\left(\mathrm{PO}_{4}\right)_{6}(\mathrm{OH})_{2} \rightarrow 10 \mathrm{CaO}+3 \mathrm{P}_{2} \mathrm{O}_{5}+\mathrm{H}_{2} \mathrm{O}$

Radikal bebas pada hidrogen peroksida akan bereaksi dengan ikatan tidak jenuh dan menyebabkan gangguan konjugasi elektron dan perubahan penyerapan energi pada molekul organik dalam struktur email dan dentin. Molekul gigi berubah struktur kimianya dengan tambahan oksigen dan akan membentuk molekul organik email yang lebih kecil ${ }^{12}$. Hidrogen peroksida mengakibatkan peningkatan ukuran diameter tubulis dentin dan menyebabkan kehilangan mineral yaitu kalsium dan fosfor email ${ }^{13}$. Hidrogen Peroksida dapat mengakibatkan denaturasi kolagen yang menyebabkan kolagen terdemineralisasi dan tidak terbentuk lapisan hibrid yang baik sehingga lapisan tersebut tidak dapat dilapisi oleh resin dan akan membentuk bagian yang lemah ${ }^{14}$.

Dari penelitian ini didapatkan bahwa pada kelompok hidrogen peroksida 35\% memiliki kecenderungan microleakage yang lebih sering daripada kelompok karbamid peroksida $35 \%$. $\mathrm{Hal}$ ini dikarenakan pada karbamid peroksida $35 \%$ setara dengan $12 \%$ hidrogen peroksida sehingga residual peroksida yang dihasilkan karbamid peroksida lebih sedikit dibandingkan 
dengan hidrogen peroksida 35\%.15 Selain itu, karbamid peroksida memiliki $\mathrm{pH}$ lebih tinggi dibanding hidrogen peroksida ${ }^{16}$.

Karbamid peroksida dapat terurai menjadi urea dan hidrogen peroksida dengan reaksi sebagai berikut:

$$
\begin{gathered}
\text { Karbamid Peroksida } \rightarrow \text { Hidrogen peroksida + Urea } \\
\mathrm{CH}_{2} \mathrm{~N}_{2} \mathrm{OH}_{2} \mathrm{O}_{2} \rightarrow \mathrm{H}_{2} \mathrm{O}_{2}+\mathrm{CH}_{2} \mathrm{~N}_{2} \mathrm{O} \\
\text { Hidrogen Peroksida } \rightarrow \text { air }+ \text { oksigen } \\
\mathrm{H}_{2} \mathrm{O}_{2} \rightarrow \mathrm{H}_{2} \mathrm{O}+\mathrm{O}_{2} \\
\text { Urea } \rightarrow \text { Amonia }+\mathrm{Karbondioksida}^{\mathrm{Am}} \\
\mathrm{CH}_{2} \mathrm{~N}_{2} \mathrm{O} \rightarrow \mathrm{NH}_{3}+\mathrm{CO}_{2}
\end{gathered}
$$

Karbamid peroksida terurai menjadi hidrogen peroksida dan urea. Hidrogen peroksida mengalami pemecahan dan bereaksi dengan ikatan tidak jenuh sehingga menghasilkan molekul yang lebih sederhana 17. Sedangkan urea dipecah menjadi karbondioksida dan ammonia yang bersifat basa sehingga akan menstabilkan hidrogen peroksida sehingga karbamid peroksida lebih lambat terurai menjadi peroksida ${ }^{18}$.

\section{KESIMPULAN}

Terdapat perbedaan pengaruh hidrogen peroksida $35 \%$ dan karbamid peroksida $35 \%$ terhadap microleakage pada resin komposit nanohybrid. Hidrogen peroksida $35 \%$ kecenderungan lebih sering terjadi microleakage dibanding karbamid peroksida $35 \%$.

\section{DAFTAR PUSTAKA}

1. Sulieman, M., 2005. An Overview of Tooth Discoloration: Extrinsic, Intrinsic and internalized Stains. Dent Update. 32: 463-471.

2. Sulieman, M., 2008. An overview of tooth-bleaching techniques: chemistry, safety and efficacy. Journal Periodontology. 48: 148-169.
3. Goldberg, M., Bohin, F., Bonnet, E., ClaisseCrinquette, A., Dartigues, J., Louis, J. J., 2007. Tooth bleaching treatment - A review. Alih Bahasa. Dupin L. Paris: Assoc Dentaire Francaise, hal 27-50.

4. Lim, M.Y., Lum, S.D.Y., Poh, R.S.C., Lee, G.P., Lim, K.C., 2004. An In Vitro Comparison of The Bleaching Efficacy of 35\% Carbamide Peroxide with Established Intracoronal Bleaching Agents. International Endodontic Journal. 37: 483-488.

5. Paramitha, A., 2012. Pemilihan Restorasi Gigi Setelah Perawatan Endodontik. Skripsi. Fakultas Kedokteran Gigi Universitas Padjajaran: Bandung.

6. Garcia A. H., Lozano M. A. M., Vila J.C., dkk. 2006. Composite Resin. A Review of The Material and Clinical Indications. Med Oral Patol Oral Cir Bucal. 11: 215-220.

7. Anusavice K.J., 2004. Buku Ajar IImu Bahan Kedokteran Gigi. Edisi 10. EGC: Jakarta, hal 228232.

8. El-Murr, J., Ruel D., St-Georges, A.J., 2011. Effects of External Bleaching on Restorative Materials: A Review, J Can Dent Assoc. 71(b59): 1-6.

9. Ellias, E., Sajjan, G., 2002. Effect of Bleaching on Microleakage of Resin Composite Restorations in Non-vital Teeth: An in-vitro study. Endodontology J. 14: 9-13.

10. Lai, S.C., Mak, Y.F., Cheung, G.S., Osorio, R., Toledano, M., Carvalho, R.M., dkk., 2001. Reversal of compromised bonding to oxidized etched dentin. J Dent Res. 80(10):1919-24.

11. Chng, H. K., Ramli, H. N., Yap, A. U. J., Lim, C. T., 2005. Effect of hydrogen peroxide on intertubular dentine. Journal of Dentistry. 33: 363-369.

12. Hendari, R., 2009. Pemutihan Gigi pada Gigi yang Mengalami Pewarnaan. Sultan Agung. XLIV (66): 6578.

13. Malekjenad, F., Ameri, H., Kianfar, I., 2012. Effect of intracoronal bleaching agents on ultrastructure and mineral content of dentin. J Conserv Dent. 15:174-7.

14. Noort, R.V., 2007. Introduction to Dental Materials. 3rd ed. Sydney: Mosby, hal 99-126.

15. Suprastiwi, E., 2005. Penggunaan Karbamid Peroksida Sebagai Bahan Pemutih Gigi. IJD. 12(3) : 139-45.

16. Ulukapi, H., Benderl, W., Ulukapi, I., 2003. Effect of pre- and postoperative bleaching on marginal leakage of amalgam and composite restorations. Quintessence international Restorative Dentistry. 34 (7) : 505-508.

17. Goldstein, R.E. dan Garber, D.A., 1995. Complete Dental Bleaching. Chicago: Quintessence Publishing Co.Inc. hal 26-33.

18. Haywood, V. B., 2003. Frequently Asked Questions About Bleaching. Compendium. 24 (4A): 324-337. 